\title{
Developments in Fractionation and Measurement of Soil Organic Carbon: A Review
}

\author{
Yadunath Bajgai $^{1,2^{*}}$, Nilantha Hulugalle ${ }^{3}$, Paul Kristiansen ${ }^{1}$, Melinda McHenry ${ }^{4}$ \\ ${ }^{1}$ School of Environmental \& Rural Science, University of New England, Armidale, Australia; ${ }^{2}$ RNR-Research and Development \\ Centre, Bajo, Department of Agriculture, MoAF, Wangdue Phodrang, Bhutan; ${ }^{3} \mathrm{NSW}$ Department of Primary Industries, Narrabri, \\ Australia; ${ }^{4}$ Centre for Plant and Water Sciences, Central Queensland University, Bundaberg, Australia. \\ Email: *ybajgai@gmail.com
}

Received October $16^{\text {th }}, 2013$; revised November $16^{\text {th }}, 2013$; accepted November $23^{\text {rd }}, 2013$

Copyright (C) 2013 Yadunath Bajgai et al. This is an open access article distributed under the Creative Commons Attribution License, which permits unrestricted use, distribution, and reproduction in any medium, provided the original work is properly cited.

\begin{abstract}
Soil organic carbon (SOC) is the percentage measure of carbon (C) derived from living organisms in soil. Stability of soil organic matter (SOM) can be defined in terms of how easily $\mathrm{C}$ and nitrogen in the SOM can be decomposed. Due to the implications in the permanence of SOC during sequestration there is scientific interest in fractionation of SOM into different fractions. A large number of SOM fractionation procedures have been developed to distinguish between SOM to study whether it is liable or recalcitrant to activities of soil microbes. There are physical and chemical fractionation techniques. The former is based on particle size and density of soil samples or combination of the two, and the latter on the reaction of chemical on SOM for the separation of stable SOC. Each fraction of SOC in the laboratory can be commonly determined using wet oxidation by Walkley-Black method and dry combustion by LECO CN Analyzer. With the advancement in chemometric statistical techniques; faster, robust, cheaper and non-destructive methods are emerging. The chemometric statistical techniques do not require any reagents for analysis compared with the wet oxidation or dry combustion methods. Thus, these emerging techniques are highly attractive for studies where a large number of analyses are required. For in situ measurement of SOC, spectral reflectance technology is developed to facilitate instant measurement in the field using the sensors or by remote sensing.
\end{abstract}

Keywords: Wet Oxidation; Dry Combustion; Chemometric Statistical Techniques

\section{Introduction}

Soil organic matter (SOM) is the vast array of carbon (C) compounds in soil and the soil organic carbon (SOC) is the $\mathrm{C}$ component of the SOM. Therefore, the SOC is the percentage measure of $\mathrm{C}$ deriving from living organisms and it is commonly represented as $\mathrm{SOM}=\mathrm{SOC} \times 1.72$, with 1.72 as the most commonly used conversion factor [1]. This is based on the assumption that SOM has 58\% $\mathrm{C}$ content, on average. It is advantageous to report SOC rather SOM for making consistent and reliable comparisons between studies. Recently, a conversion factor of 2.0 was proposed to be more accurate and representative based on the fact that most of the published literature averaged content of $50 \% \mathrm{C}$ rather than $58 \%$ [2]. Slight change in the SOC stock is reported to influence atmospheric $\mathrm{C}$ concentration and the fluxes of SOC differ in response to environmental conditions and land manage-

\footnotetext{
${ }^{*}$ Corresponding author.
}

ment factors [3]. Stability of SOC can be studied using fractionation techniques. This paper summarises the methods of SOC fractionation which helps us understand the characteristic of SOC specially its stability, and provides the summary of main methods used for measurement of SOC in the laboratory and field.

\section{Fractionation of SOC}

\subsection{Need for SOC Fractionation}

Stability of SOM can be defined in terms of how easily C and nitrogen in the SOM can be decomposed. The identification, isolation and characterisation of SOM fractions have received a great deal of scientific interest because of their implications in the permanence of SOC during sequestration [4,5]. The estimates of different pools are used in mechanistic models (e.g. Roth-C and Century) that predict changes in SOM storage [6,7]. A large number of SOM fractionation procedures have been devel- 
oped that seek to distinguish between SOM that is more easily decomposed (low stability) and less easily decomposed (high stability) by the soil microbes. The procedures have been recently reviewed and include physical fractionation by size or density, and various chemical fractionation methods that separate SOM by solubility, hydrolysability, or resistance to oxidation $[3,8]$.

\subsection{Physical Fraction by Particle Size}

Physical fractionation procedures by size is based on the idea that the association of soil particles and their spatial arrangement play a key role in SOM dynamics as bioaccessibility is a prerequisite for decomposition $[9,10]$. Physical fractionation involves the application of various degrees of disaggregating treatments by dry and wet sieving [11-13], dispersion [14], and density separation and sedimentation $[11,15]$. The extraction method developed by Cambardella and Elliott [14] is commonly used to isolate particulate $(>53 \mu \mathrm{m})$ and mineral-associated organic $\mathrm{C}$ fractions $(<53 \mu \mathrm{m})$ after dispersion of soil samples in potassium hexa-meta phosphate solution ( $5 \mathrm{~g}$ $\mathrm{L}^{-1}$ ) and tumbled overnight. Based on the extraction component of Cambardella and Elliott [14], an automated wet sieving technique was developed in Australia using $50 \mu \mathrm{m}$ sieve so that $>50 \mu \mathrm{m}$ fraction consists of particulate organic matter (POM) plus sand and $<50 \mu \mathrm{m}$ fraction of mineral-associated organic matter [16].

\subsection{Combination of Size and Density Fraction}

The general wet sieving process uses sieves of $250 \mu \mathrm{m}$ and $53 \mu \mathrm{m}$ to isolate fractions into three aggregate groups. The $>250 \mu \mathrm{m}$ is macroaggregate, 250 - $53 \mu \mathrm{m}$ is microaggragate and $<53 \mu \mathrm{m}$ is silt + clay size fraction $[12,13]$. Density fractionation is applied to isolate SOM that is not firmly associated with soil minerals from organo-mineral complexes $[11,15]$. Associations of SOM to mineral surfaces are most often characterised by a density $>1.6-2 \mathrm{~g}$ $\mathrm{cm}^{-3}$. The fraction of SOM that floats in the $>1.6-2 \mathrm{~g}$ $\mathrm{cm}^{-3}$ medium is the light fraction and that settles down is the heavy fraction. Lighter fraction or POM with a density of $<1.6-2 \mathrm{~g} \mathrm{~cm}^{-3}$ consists mostly of pieces of plant residues and heavier fraction consists of mineral-associated organic $C[11,15]$. POM also has been separated by a combination of size and density fractionation [17-19] in several steps for each particle size group.

\subsection{Chemical Fractionation of SOC}

Of the five SOC pools in the Roth-C model, the inert pool [6] is considered to be totally unaffected by microbial attack and thus to undergo no decomposition with time [20]. Several chemical fractionation methods have been used for the isolation of stable SOC; hydrolysis using trifluoroacetic acid (TFA) and hydrochloric acid
( $\mathrm{HCl})[21,22]$, oxidative treatments using several oxidants like hydrogen peroxide $\left(\mathrm{H}_{2} \mathrm{O}_{2}\right)$ [23], disodium peroxodisulphate $\left(\mathrm{Na}_{2} \mathrm{~S}_{2} \mathrm{O}_{8}\right)$ [24], or sodium hypochlorite $(\mathrm{NaOCl})$ [25]. Hydrolysis removes compounds that are supposed to be potentially biodegradable $[21,22]$, whereas it has been suggested that the treatments using oxidizing reagents to mimic biodegradation to the extent that treatments preferentially remove less protected SOC [23, 25]. Helfrich et al. [26] compared five chemical fractionation methods and found that all chemical treatments caused a preferential removal of young, maize-derived SOC, with $\mathrm{Na}_{2} \mathrm{~S}_{2} \mathrm{O}_{8}$ and $\mathrm{H}_{2} \mathrm{O}_{2}$ being most efficient. However, none of the methods were reported to be generally suited for the determination of the inert organic matter pool of the Roth-C model [26].

\section{Measurement of SOC}

\subsection{Wet Oxidation and Dry Combustion Methods}

The most commonly used methods for determination of SOC are wet oxidation by Walkley-Black method [27] and dry combustion by LECO CN Analyzer [28]. The latter method estimates SOC more accurately. Due to incomplete oxidation of SOC in a dichromate-sulphuric acid mixture, the Walkley-Black method underestimates SOC concentration when no heating is applied. To overcome the problem of incomplete $\mathrm{C}$ recovery, which leads to the underestimation of $\mathrm{C}$ concentrations by WalkleyBlack method, the analytical results of this technique are adjusted by 1.32 as a correction factor assuming the recovery rate of $76 \%$ [29]. However, modified dichromate oxidation techniques that involve extensive heating do not require a correction factor because most of the organic $\mathrm{C}$ in the soil is oxidized to $\mathrm{CO}_{2}$ [27]. Some authors reported that the recovery of $76 \%$ is generally too large $[30,31]$ and that it may vary according to land use, soil texture and sampling depth [30-32].

\subsection{Chemometric Statistical Methods}

With the development and emergence of reflectance spectroscopy techniques, near infrared (NIR) and mid-infrared (MIR) are also used to determine SOC in the laboratory. Using chemometric statistical methods, both NIR and MIR spectroscopy techniques have been used in the past two decades to determine soil properties, including soil organic $\mathrm{C}$ and total nitrogen [33-35]. Compared with wet and dry combustion methods, the NIR and MIR spectroscopy techniques are faster, robust, cheaper and non-destructive, and they do not require any reagents for analysis [36,37]. These emerging techniques are, therefore, likely to replace the tedious job of wet and dry combustions in future, and are highly attractive for studies where a large number of analyses are required [34]. 


\subsection{In Situ Methods}

The techniques used for in situ measurement of SOC in the field are by sampling, or by on-the-go detection with sensors mounted on a tractor $[38,39]$ that facilitate instant measurement of SOC. These methods are also non-destructive and relatively cheaper compared to the destructive wet laboratory [27] or dry combustion [28] methods. Remote sensing is another tool for in situ measurement of soil properties in the field $[40,41]$ based on spectral laboratory data and this method captures large spatial area unlike the other previously mentioned techniques. The other in situ methods include Laser-Induced Breakdown Spectroscopy and Inelastic Neutron Scattering techniques [41]. A recent review covers more detail on SOC dynamics with fractionation and measurement techniques [3].

\section{Conclusion}

It is advantageous to report SOC rather SOM to consistently and reliably compare between studies. Due to the implications in the permanence of SOC during sequestration, there is a need to fractionate of SOM into different fractions. Further, mechanistic models that predict changes in SOM storage require the estimates of different SOC pools. Thus, a large number of SOM fractionation procedures have been developed to distinguish between SOM to study whether it is liable or recalcitrant. Once fractionated, the most common methods for determination of SOC in laboratory are wet oxidation and dry combustion. More advanced; chemometric statistical techniques are faster, robust, cheaper and non-destructive than wet oxidation and dry combustion methods. With the advancement in spectral reflectance technology, the in situ measurement of SOC is done using with sensors or by remote sensing to facilitate instant measurement of SOC in the field.

\section{Acknowledgements}

The first author, a Bhutanese national, was funded by the Endeavour Postgraduate Award of Australia Awards at the University of New England, Armidale, Australia for his PhD study.

\section{REFERENCES}

[1] J. A. Baldock and J. O. Skjemstad, "Soil Organic Carbon/Soil Organic Matter," CSIRO Publishing, Melbourne, 1999.

[2] D. W. Pribyl, "A Critical Review of the Conventional SOC to SOM Conversion Factor," Geoderma, Vol. 156, No. 3-4, 2010, pp. 75-83. http://dx.doi.org/10.1016/j.geoderma.2010.02.003

[3] U. Stockmann, M. A. Adams, J. W. Crawford, D. J. Field,
N. Henakaarchchi, M. Jenkins, B. Minasny, A. B. McBratney, V. D. R. D. Courcelles, K. Singh, I. Wheeler, L. Abbott, D. A. Angers, J. Baldock, M. Bird, P. C. Brookes, C. Chenu, J. D. Jastrow, R. Lal, J. Lehmann, A. G. O'Donnell, W. J. Parton, D. Whitehead and M. Zimmermann, "The Knowns, Known Unknowns and Unknowns of Sequestration of Soil Organic Carbon," Agriculture, Ecosystems \& Environment, Vol. 164, 2013, pp. 80-99. http://dx.doi.org/10.1016/j.agee.2012.10.001

[4] A. F. Plante, J. M. Fernández, M. L. Haddix, J. M. Steinweg and R. T. Conant, "Biological, Chemical and Thermal Indices of Soil Organic Matter Stability in Four Grassland Soils," Soil Biology and Biochemistry, Vol. 43, No. 5, 2011, pp. 1051-1058.

http://dx.doi.org/10.1016/j.soilbio.2011.01.024

[5] Y. Bajgai, "Effect of Alterative Cropping Management on Soil Organic Carbon," PhD Thesis, University of New England, Armidale, 2013.

[6] K. Coleman, D. S. Jenkinson, G. J. Crocker, P. R. Grace, J. Klír, M. Körschens, P. R. Poulton and D. D. Richter, "Simulating Trends in Soil Organic Carbon in Long-Term Experiments Using RothC-26.3," Geoderma, Vol. 81, No. 1-2, 1997, pp. 29-44.

http://dx.doi.org/10.1016/S0016-7061(97)00079-7

[7] W. J. Parton, D. S. Schimel, C. V. Cole and D. S. Ojima, "Analysis of Factors Controlling Soil Organic Matter Levels in Great Plains Grasslands," Soil Science Society of America Journal, Vol. 51, No. 5, 1987, pp. 1173-1179. http://dx.doi.org/10.2136/sssaj1987.03615995005100050 $\underline{015 x}$

[8] M. von Lützow, I. Kögel-Knabner, K. Ekschmitt, H. Flessa, G. Guggenberger, E. Matzner and B. Marschner, "SOM Fractionation Methods: Relevance to Functional Pools and to Stabilization Mechanisms," Soil Biology and Biochemistry, Vol. 39, No. 9, 2007, pp. 2183-2207. http://dx.doi.org/10.1016/j.soilbio.2007.03.007

[9] B. T. Christensen, "Physical Fractionation of Soil and Structural and Functional Complexity in Organic Matter Turnover," European Journal of Soil Science, Vol. 52, No. 3, 2001, pp. 345-353. http://dx.doi.org/10.1046/j.1365-2389.2001.00417.x

[10] H. Blanco-Canqui and R. Lal, "Mechanisms of Carbon Sequestration in Soil Aggregates," Critical Reviews in Plant Sciences, Vol. 23, No. 6, 2004, pp. 481-504. http://dx.doi.org/10.1080/07352680490886842

[11] B. T. Christensen, "Physical Fractionation of Soil and Organic Matter in Primary Particle Size and Density Separates," Advances in Soil Science, Vol. 20, 1992, pp. 1-90.

[12] J. Six, E. T. Elliott and K. Paustian, "Aggregate and soil organic Matter Dynamics under Conventional and NoTillage Systems," Soil Science Society of America Journal, Vol. 63, No. 5, 1999, pp. 1350-1358. http://dx.doi.org/10.2136/sssaj1999.6351350x

[13] J. Six, E. T. Elliott and P. K., "Soil Macroaggregate Turnover and Microaggregate Formation: A Mechanism for C Sequestration under No-Tillage Agriculture," Soil Biology and Biochemistry, Vol. 32, No. 14, 2000, pp. 2099-2103.

http://dx.doi.org/10.1016/S0038-0717(00)00179-6 
[14] C. A. Cambardella and E. T. Elliott, "Particulate Soil Organic-Matter Changes across a Grassland Cultivation Sequence," Soil Science Society of America Journal, Vol. 56, No. 3, 1992, pp. 777-783.

http://dx.doi.org/10.2136/sssaj1992.03615995005600030 $\underline{017 x}$

[15] A. Golchin, J. M. Oades, J. O. Skjemstad and P. Clarke, "Soil Structure and Carbon Cycling," Australian Journal of Soil Research, Vol. 32, No. 5, 1994, pp. 1043-1068. http://dx.doi.org/10.1071/SR9941043

[16] J. Sanderman, J. Baldock, B. Hawke, L. Macdonald, A. Massis-Puccini and S. Szarvas, "National Soil Carbon Research Programme: Field and Laboratory Methodologies," CSIRO, Land and Water, Urrbrae, 2011.

[17] J. Balesdent, E. Besnard, D. Arrouays and C. Chenu, "The Dynamics of Carbon in Particle-Size Fractions of Soil in a Forest-Cultivation Sequence," Plant and Soil, Vol. 201, No. 1, 1998, pp. 49-57. http://dx.doi.org/10.1023/A:1004337314970

[18] J. Six, E. T. Elliott, K. Paustian and J. W. Doran, "Aggregation and Soil Organic Matter Accumulation in Cultivated and Native Grassland Soils," Soil Science Society of America Journal, Vol. 62, No. 5, 1998, pp. 1367-1377. http://dx.doi.org/10.2136/sssaj1998.03615995006200050 $\underline{032 x}$

[19] J. Six, R. Merckx, K. Kimpe, K. Paustian and E. T. Elliott, "A Re-Evaluation of the Enriched Labile Soil Organic Matter Fraction," European Journal of Soil Science, Vol. 51, No. 2, 2000, pp. 283-293.

http://dx.doi.org/10.1046/j.1365-2389.2000.00304.x

[20] P. Falloon, P. Smith, K. Coleman and S. Marshall, "How Important Is Inert Organic Matter for Predictive Soil Carbon Modelling Using the Rothamsted Carbon Model?" Soil Biology and Biochemistry, Vol. 32, No. 3, 2000, pp. 433-436. http://dx.doi.org/10.1016/S0038-0717(99)00172-8

[21] K. Quénéa, S. Derenne, C. Largeau, C. Rumpel and A. Mariotti, "Influence of Change in Land Use on the Refractory Organic Macromolecular Fraction of a Sandy Spodosol (Landes de Gascogne, France)," Geoderma, Vol. 136, No. 1-2, 2006, pp. 136-151.

http://dx.doi.org/10.1016/j.geoderma.2006.03.018

[22] N. Poirier, S. Derenne, J. Balesdent, A. Mariotti, D. Massiot and C. Largeau, "Isolation and Analysis of the NonHydrolysable Fraction of a Forest Soil and an Arable Soil (Lacadee, Southwest France)," European Journal of Soil Science, Vol. 54, No. 2, 2003, pp. 243-255. http://dx.doi.org/10.1046/j.1365-2389.2003.00520.x

[23] A. F. Plante, C. Chenu, M. Balabane, A. Mariotti and D. Righi, "Peroxide Oxidation of Clay-Associated Organic Matter in a Cultivation Chronosequence," European Journal of Soil Science, Vol. 55, No. 3, 2004, pp. 471-478. http://dx.doi.org/10.1111/j.1365-2389.2004.00626.x

[24] K. Eusterhues, C. Rumpel, M. Kleber and I. KögelKnabner, "Stabilisation of Soil Organic Matter by Interactions with Minerals as Revealed by Mineral Dissolution and Oxidative Degradation," Organic Geochemistry, Vol. 34, No. 12, 2003, pp. 1591-1600. http://dx.doi.org/10.1016/j.orggeochem.2003.08.007
[25] M. Kleber, R. Mikutta, M. S. Torn and R. Jahn, "Poorly Crystalline Mineral Phases Protect Organic Matter in Acid Subsoil Horizons," European Journal of Soil Science, Vol. 56, No. 6, 2005, pp. 717-725.

http://dx.doi.org/10.1016/j.geoderma.2004.12.018

[26] M. Helfrich, H. Flessa, R. Mikutta, A. Dreves and B. Ludwig, "Comparison of Chemical Fractionation Methods for Isolating Stable Soil Organic Carbon Pools," European Journal of Soil Science, Vol. 58, No. 6, 2007, pp. 1316-1329. http://dx.doi.org/10.1111/j.1365-2389.2007.00926.x

[27] S. J. Kalembasa and D. S. Jenkinson, "A Comparative Study of Titrimetric and Gravimetric Methods for the Determination of Organic Carbon in Soil," Journal of the Science of Food and Agriculture, Vol. 24, No. 9, 1973, pp. 1085-1090. http://dx.doi.org/10.1002/jsfa.2740240910

[28] D. W. Nelson and L. E. Sommers, "Total Carbon, Organic Carbon and Organic Matter," In: D. L. Sparks, A. L. Page, P. A. Helmke and R. H. Loeppert, Eds., Methods of Soil Analysis Part 3-Chemical Methods, ASA, SSSA, Inc. Madison, 1996, pp. 961-1010.

[29] G. P. Gillman, D. F. Sinclair and T. A. Beech, "Recovery of Organic Carbon by the Walkley and Black Procedure in Highly Weathered Soils," Communications in Soil Science and Plant Analysis, Vol. 17, No. 8, 1986, pp. 885892. http://dx.doi.org/10.1080/00103628609367759

[30] K. R. Brye and N. A. Slaton, "Carbon and Nitrogen Storage in a Typic Albaqualf as Affected by Assessment Method," Communications in Soil Science and Plant Analysis, Vol. 34, No. 11-12, 2003, pp. 1637-1655. http://dx.doi.org/10.1081/CSS-120021302

[31] M. Diaz-Zorita, "Soil Organic Carbon Recovery by the Walkley-Black Method in a Typic Hapludoll," Communications in Soil Science and Plant Analysis, Vol. 30, No. 5-6, 1999, pp. 739-745. http://dx.doi.org/10.1080/00103629909370242

[32] S. Lettens, B. De Vos, P. Quataert, B. Van Wesemael, B. Muys and J. Van Orshoven, "Variable Carbon Recovery of Walkley-Black Analysis and Implications for National Soil Organic Carbon Accounting," European Journal of Soil Science, Vol. 58, No. 6, 2007, pp. 1244-1253. http://dx.doi.org/10.1111/j.1365-2389.2007.00916.x

[33] L. J. Janik, R. H. Merry and J. O. Skjemstad, "Can Mid Infrared Diffuse Reflectance Analysis Replace Soil Extractions?" Australian Journal of Experimental Agriculture, Vol. 38, No. 7, 1998, pp. 681-696. http://dx.doi.org/10.1071/EA97144

[34] X. M. Yang, H. T. Xie, C. F. Drury, W. D. Reynolds, J. Y. Yang and X. D. Zhang, "Determination of Organic Carbon and Nitrogen in Particulate Organic Matter and Particle Size Fractions of Brookston Clay Loam Soil Using Infrared Spectroscopy," European Journal of Soil Science, Vol. 63, No. 2, 2012, pp. 177-188.

http://dx.doi.org/10.1111/j.1365-2389.2011.01421.x

[35] M. Zimmermann, J. Leifeld and J. Fuhrer, "Quantifying Soil Organic Carbon Fractions by Infrared-Spectroscopy," Soil Biology and Biochemistry, Vol. 39, No. 1, 2007, pp. 224-231.

http://dx.doi.org/10.1016/j.soilbio.2006.07.010 
[36] L. J. Janik, J. O. Skjemstad, K. D. Shepherd and L. R. Spouncer, "The Prediction of Soil Carbon Fractions Using Mid-Infrared-Partial Least Square Analysis," Soil Research, Vol. 45, No. 2, 2007, pp. 73-81. http://dx.doi.org/10.1071/SR06083

[37] G. M. Vasques, S. Grunwald and J. O. Sickman, "Comparison of Multivariate Methods for Inferential Modeling of Soil Carbon Using Visible/Near-Infrared Spectra," Geoderma, Vol. 146, No. 1-2, 2008, pp. 14-25. http://dx.doi.org/10.1016/j.geoderma.2008.04.007

[38] V. Bellon-Maurel and A. McBratney, "Near-Infrared (NIR) and Mid-Infrared (MIR) Spectroscopic Techniques for Assessing the Amount of Carbon Stock in SoilsCritical Review and Research Perspectives," Soil Biology and Biochemistry, Vol. 43, No. 7, 2011, pp. 1398-1410. http://dx.doi.org/10.1016/j.soilbio.2011.02.019

[39] L. Cécillon, B. G. Barthès, C. Gomez, D. Ertlen, V.
Genot, M. Hedde, A. Stevens and J. J. Brun, "Assessment and Monitoring of Soil Quality Using Near-Infrared Reflectance Spectroscopy (NIRS)," European Journal of Soil Science, Vol. 60, No. 5, 2009, pp. 770-784. http://dx.doi.org/10.1111/j.1365-2389.2009.01178.x

[40] E. Ben-Dor, K. Patkin, A. Banin and A. Karnieli, "Mapping of Several Soil Properties Using DAIS-7915 Hyperspectral Scanner Data-A Case Study over Clayey Soils in Israel," International Journal of Remote Sensing, Vol. 23, No. 6, 2002, pp. 1043-1062. http://dx.doi.org/10.1080/01431160010006962

[41] A. Chatterjee, R. Lal, L. Wielopolski, M. Z. Martin and M. H. Ebinger, "Evaluation of Different Soil Carbon Determination Methods," Critical Reviews in Plant Sciences, Vol. 28, No. 3, 2009, pp. 164-178. http://dx.doi.org/10.1080/07352680902776556 